\title{
The highly selective oxidation
} of cyclohexane to cyclohexanone and cyclohexanol over VAIPO ${ }_{4}$ berlinite by oxygen under atmospheric pressure

Yun Hong, Dalei Sun ${ }^{*}$ and Yanxiong Fang

\begin{abstract}
Background: The oxidation of cyclohexane under mild conditions occupies an important position in the chemical industry. A few soluble transition metals were widely used as homogeneous catalysts in the industrial oxidation of cyclohexane. Because heterogeneous catalysts are more manageable than homogeneous catalysts as regards separation and recycling, in our study, we hydrothermally synthesized and used pure berlinite $\left(\mathrm{AlPO}_{4}\right)$ and vanadiumincorporated berlinite $\left(\mathrm{VAIPO}_{4}\right)$ as heterogeneous catalysts in the selective oxidation of cyclohexane with molecular oxygen under atmospheric pressure. The catalysts were characterized by means of by XRD, FT-IR, XPS and SEM. Various influencing factors, such as the kind of solvents, reaction temperature, and reaction time were investigated systematically.
\end{abstract}

Results: The XRD characterization identified a berlinite structure associated with both the $\mathrm{AlPO}_{4}$ and $\mathrm{VAIPO}$ catalysts. The FT-IR result confirmed the incorporation of vanadium into the berlinite framework for VAIPO ${ }_{4}$. The XPS measurement revealed that the oxygen ions in the $\mathrm{VAlPO}_{4}$ structure possessed a higher binding energy than those in $\mathrm{V}_{2} \mathrm{O}_{5}$, and as a result, the lattice oxygen was existed on the surface of the $\mathrm{VAIPO}_{4}$ catalyst. It was found that $\mathrm{VAIPO}_{4}$ catalyzed the selective oxidation of cyclohexane with molecular oxygen under atmospheric pressure, while no activity was detected on using $\mathrm{AlPO}_{4}$. Under optimum reaction conditions (i.e. a $100 \mathrm{~mL}$ cyclohexane, $0.1 \mathrm{MPa} \mathrm{O}_{2}, 353 \mathrm{~K}, 4 \mathrm{~h}, 5 \mathrm{mg}$ $\mathrm{VAIPO}_{4}$ and $20 \mathrm{~mL}$ acetic acid solvent), a selectivity of KA oil (both cyclohexanol and cyclohexanone) up to $97.2 \%$ (with almost 6.8\% conversion of cyclohexane) was obtained. Based on these results, a possible mechanism for the selective oxidation of cyclohexane over $\mathrm{VAIPO}_{4}$ was also proposed.

Conclusions: As a heterogeneous catalyst $\mathrm{VAIPO}_{4}$ berlinite is both high active and strong stable for the selective oxidation of cyclohexane with molecular oxygen. We propose that KA oil is formed via a catalytic cycle, which involves activation of the cyclohexane by a key active intermediate species, formed from the nucleophilic addition of the lattice oxygen ion with the carbon in cyclohexane, as well as an oxygen vacancy formed at the $\mathrm{VAlPO}_{4}$ catalyst surface.

Keywords: Oxidation, Cyclohexane, Heterogeneous catalyst, Berlinite

\section{Introduction}

With the development of petrochemical industry, the oxidation of cyclohexane under mild conditions, with molecular oxygen or air, is of great interest $[1,2]$. In the

*Correspondence: sdlei80@163.com

Department of Chemical Engineering and Light Industry, Guangdong

University of Technology, Guangzhou 510006, China autoxidation of cyclohexane, most industrial processes are involved with the usage of soluble transition metal catalysts, including vanadium oxide, at $423 \sim 453 \mathrm{~K}$ and afford the mixture of cyclohexanol, cyclohexanone and dicarboxylic acids, which is formed by further oxidation of cyclohexanone and cyclohexanol [2,3]. However, the use of soluble metal catalysts in these systems often requires a tedious catalyst separation step [4]. Thus, it is 
necessary to develop effective recyclable heterogeneous catalysts for selective oxidation of cyclohexane by $\mathrm{O}_{2}$.

The AlPO-n families are divided into two groups: dense-phase berlinite or tridymite and porous aluminophosphate molecular sieve [5]. Berlinite is the nonporous and stable phase of polymorphous aluminophosphates [6] and potentially mainly used in functional material fields, such as acoustic wave device, memory glass [7] and piezoelectric material [8], as well as, high-performance sealants for corrosion- and wearresistant coatings [9]. Porous aluminophosphates and their derivates (MeAPO-n) incorporated with transition metals were widely used as catalysts, including VAPO-5 molecular sieves [3]. For example, they have been frequently used as catalysts for the selective oxidation of cyclohexane to produce cyclohexanol and cyclohexanone $[10,11]$. At the same time, the heterogeneous MeAPO-n molecular sieve as catalysts is a very controversial issue and it is generally recognized that metals are leached into the polar solvents, such as acetic acid [12].

Berlinite is more stable than MeAPO-n molecular sieve $[5,6]$. But they had seldom been applied in catalytic cyclohexane oxidation. Accordingly, we report the application for the first time as well as the preparation, characterization and catalytic performance in cyclohexane oxidation of a new $\mathrm{VAlPO}_{4}$ berlinite, in which vanadium was incorporated. It is found to be an active recyclable heterogeneous catalyst for the selective oxidation of cyclohexane with molecular oxygen under mild conditions.

\section{Experiment}

\section{Catalyst preparation}

$\mathrm{Al}\left(\mathrm{CH}_{3} \mathrm{COO}\right)_{3} \cdot 2 \mathrm{H}_{2} \mathrm{O}, \mathrm{H}_{3} \mathrm{PO}_{4}$ (85\% sol in water), and $\mathrm{V}_{2} \mathrm{O}_{5}$ were used as the sources of aluminum, phosphorus, vanadium, and triethyl amine $\left(\mathrm{Et}_{3} \mathrm{~N}\right)$ was used as template. $\mathrm{VAlPO}_{4}$ berlinite was synthesized from the gel according to the following molar ratio: $0.02 \mathrm{~V}: 0.92 \mathrm{Al}: 1.0$ $\mathrm{P}: 0.81 \mathrm{Et}_{3} \mathrm{~N}: 30 \mathrm{H}_{2} \mathrm{O}$. During typical synthesis, $\mathrm{Al}(\mathrm{OAc})_{3}$ was hydrolyzed firstly at room temperature for $2 \mathrm{~h}$, and aqueous solution of $\mathrm{V}_{2} \mathrm{O}_{5}$ and $\mathrm{H}_{3} \mathrm{PO}_{4}$ was added into the obtained solution. The formed mixture was stirred at room temperature for $2 \mathrm{~h}$ and $\mathrm{Et}_{3} \mathrm{~N}$ were then added into the homogeneous gel at $273 \mathrm{~K}$ under vigorous stirring. Finally, the mixture was stirred at $273 \mathrm{~K}$ for another $3 \mathrm{~h}$. The final gel was charged in a Teflon-lined autoclave and allowed to crystallize at $453 \mathrm{~K}$ for $48 \mathrm{~h}$. The $\mathrm{VAlPO}_{4}$ berlinite was filtered and washed several times with deionized water until the $\mathrm{pH}$ value was 7 . The crystals were dried at $373 \mathrm{~K}$ for $6 \mathrm{~h}$ and then calcined at $823 \mathrm{~K}$ for $10 \mathrm{~h}$ to remove the $\mathrm{Et}_{3} \mathrm{~N}$ template.

VAlPO-5 molecular sieve was also synthesized according the method reported by Concepción et al. [3].

\section{Characterization}

XRD was performed on a Brucker D8 Advance diffractometer with $\mathrm{Cu} K \alpha 1$ radiation according to the scanning range of $2 \theta=6-80^{\circ}$ at a rate of $1 \% \mathrm{~min}$. Fourier transform infrared (FT-IR) spectroscopy was conducted on a Varian 3100 spectrometer in transmission mode with the resolution of $4 \mathrm{~cm}^{-1}$. The $\mathrm{VAlPO}_{4}$ specimen was mixed with $\mathrm{KBr}$ according to the weight ratio of 1:200 and pressed into pellets for measurement. The spectra were recorded as the accumulated results of 125 scans and the spectra of dry $\mathrm{KBr}$ were selected for background subtraction. X-ray photoelectron spectroscopy (XPS) was carried out on a Phi Quantum 2000 Scanning ESCA Microprobe with Al $\mathrm{K} \alpha$ radiation. A C1s binding energy of $284.6 \mathrm{eV}$ was used as the reference. Microphotography and EDAX analyses were performed on a Philips SEM 505 instrument equipped with an EDAX detecting unit. Chemical analyses of $\mathrm{V}$ content were performed by atomic absorption spectroscopy (AAS) with a Varian AA240 spectrometer. The chemical compositions determined with EDAX were compared with the results obtained by XPS and the content of vanadium obtained by AAS analyses of the solutions prepared by thermal acid digestion of the sample.

\section{Catalytic reaction}

The catalytic performance of $\mathrm{VAlPO}_{4}$ berlinite was tested through cyclohexane $(\geq 99.5 \%$, without further purification, Beijing Chem. Corp.) oxidation as model reaction with molecular oxygen under atmospheric pressure. The reaction was carried out at $348 \mathrm{~K}$ in a $250 \mathrm{~mL}$ three-neck flask equipped with a condenser. Typically, $80 \mathrm{~g}$ cyclohexane, $40 \mathrm{~g}$ acetic acid (used as solvent), $0.5 \mathrm{~g}$ cyclohexanone (used as initiator) and $0.5 \mathrm{~g}$ catalyst were added into the three-neck flask at room temperature. Then, the reactor was heated to the reaction temperature and the reaction solution was stirred with an external magnetic stirrer. At the reaction temperature, the reactor was charged with a flow of $\mathrm{O}_{2}$. The flow rate of the $\mathrm{O}_{2}$ was controlled in the way that bubbles of oxygen appeared in the solution and that no oxygen could be detected in the outlet of the condenser to ensure that oxygen was totally consumed by the oxidation of cyclohexane. After $6 \mathrm{~h}$, the reaction stopped. After cooling down to room temperature, the reaction mixture was diluted with $20 \mathrm{~g}$ ethanol to produce a homogeneous solution and then the catalyst was separated through filtration. The filtration solution was used for composition analysis.

To examine the stability of the catalyst, the solution of product mixtures obtained from the oxidation of cyclohexane as mentioned above was filtered to remove the catalyst. The obtained solution was used directly as the reactant without the addition of catalyst, cyclohexanone and acetic acid and subjected to the oxidative 
reaction in the same condition: reaction temperature of $348 \mathrm{~K}$, the oxidant of molecular oxygen and atmospheric pressure. After $10 \mathrm{~h}$, the reaction stopped. The product mixture was sampled and analyzed.

The reaction products were analyzed by GC-MS and HPLC for identification (Additional files 1 and 2). The quantitative analyses of cyclohexanol and cyclohexanone were carried out by Agilent 4890D gas chromatography with OV-1701 column $(30 \mathrm{~m} \times 0.25 \mathrm{~mm} \times 0.3 \mu \mathrm{m})$ and the internal standard of methylbenzene. The carboxylic acids were analyzed on Agilent 1100 Series HPLC instrument with a $250 \times 4.6 \mathrm{~mm}$ Microsorb-MV (C18) column and an ultraviolet detector. The analysis conditions were provided as follows: flow phase of water/ methanol $(10 \sim 30 \%) / \mathrm{KH}_{3} \mathrm{PO}_{4}(5 \mathrm{mM})$, $\mathrm{pH}$ value $(3 \sim 4)$ of flow phase adjusted with $\mathrm{H}_{3} \mathrm{PO}_{4}(25 \%)$, flow rate of $1.0 \mathrm{~mL} \mathrm{~min}{ }^{-1}$, column temperature of $298 \mathrm{~K}$ and ultraviolet wavelength of $212 \mathrm{~nm}$. The contents of byproducts acid were determined according to external standard method and calculated according to the equation $\mathrm{W}_{s p}=\mathrm{W}_{s t} \cdot \mathrm{A}_{s p} / \mathrm{A}_{s t} \times 100 \%$, where $s p$ and $s t$ indicated specimen and standard, respectively. The conversion rate of cyclohexane and the yield of cyclohexanol and cyclohexanone were calculated according to the converted cyclohexane.

The solid catalyst was separated by filtration and washed with $20 \mathrm{~mL}$ of acetone, and then dried at $373 \mathrm{~K}$ for $2 \mathrm{~h}$ after each reaction.

\section{Results and discussion Characterization}

Figure 1 shows the XRD pattern of the $\mathrm{VAlPO}_{4}$ berlinite, which is totally consistent with that of standard berlinite (JCPDS No. 76-227). Other crystalline or amorphous phases were not detected.

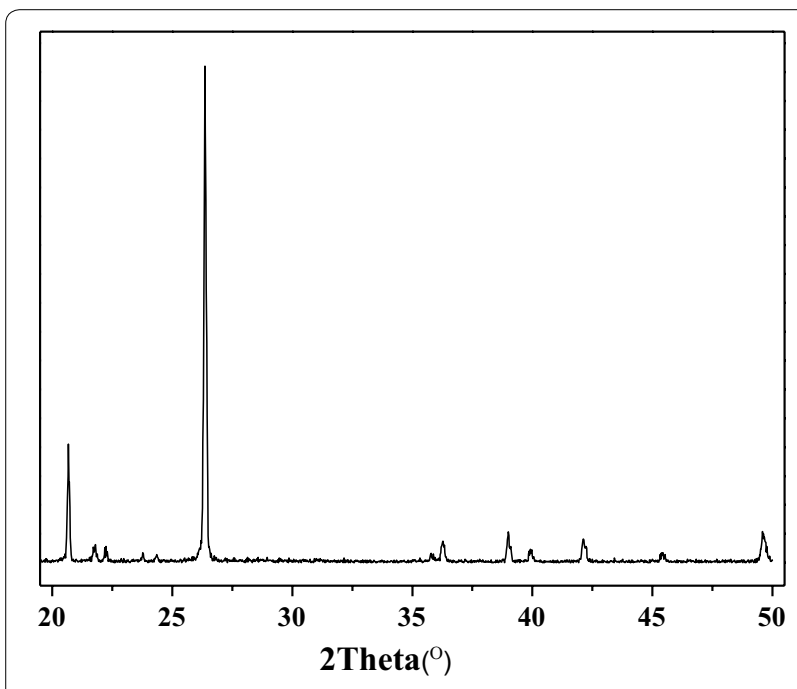

Fig. 1 XRD pattern of the $\mathrm{VAIPO}_{4}$ catalyst
The microphotographs (Fig. 2) show the snowflake structure shape of $\mathrm{VAlPO}_{4}$ berlinite, without the presences of any other amorphous phases. The catalyst compositions determined by EDAX and AAS analyses are summarized as follows: $0.23 \mathrm{~V}_{2} \mathrm{O}_{5}: 1.00 \mathrm{Al}_{2} \mathrm{O}_{3}: 1.14$ $\mathrm{P}_{2} \mathrm{O}_{5}$ for $\mathrm{VAlPO}_{4}$ berlinite. The chemical composition determined by EDAX is in good agreement with those obtained by AAS analysis, indicating the uniform distribution of the vanadium in the $\mathrm{VAIPO}_{4}$ berlinite. The mapping of a $20 \mu \mathrm{m}$ crystal of the sample at fifteen different points showed a practically constant composition, indicating the homogeneous distribution of vanadium in the crystal.

After calcination at $823 \mathrm{~K}$ in air, according to the subsequent determination results by FT-IR spectroscopy (Fig. 3), the template was completely removed. The spectrum of the $\mathrm{VAlPO}_{4}$ catalyst exhibited the characteristic vibration absorptions of a berlinite structure $[5,6,13-$ 16], i.e. the bands at $1128 \mathrm{~cm}^{-1}$ are ascribed to the asymmetric $\mathrm{Al}-\mathrm{O}$ and/or P-O stretching modes and the bands at $804 \mathrm{~cm}^{-1}$ are ascribed to the symmetric $\mathrm{Al}-\mathrm{O}$ and/or $\mathrm{P}-\mathrm{O}$ stretch in $\mathrm{TO}_{4}(\mathrm{~T}=\mathrm{Al}$ or $\mathrm{P})[5,6,15]$, the bands at 684 and $458 \mathrm{~cm}^{-1}$ are assigned to the $\mathrm{Al}-\mathrm{O}$ and/or $\mathrm{P}-\mathrm{O}$ bending modes $[5,15,16]$, and some of which were shifted towards lower wavenumbers probably due to the incorporation of $\mathrm{V}$ into the berlinite framework. In addition, a few additional bands at 1089, 747, 684, 653, and $566 \mathrm{~cm}^{-1}$ were also detected in the $\mathrm{VAlPO}_{4}$ spectrum compared to that for $\mathrm{AlPO}_{4}$ [16-18]. Thus, the bands at $1089,747,684,653$, and $566 \mathrm{~cm}^{-1}$ should be caused by the incorporation of $\mathrm{V}$ into the berlinite and assigned to the vibrations of V-O-P $[13,19]$, providing further evidence for the incorporation of $\mathrm{V}$ into the berlinite framework.

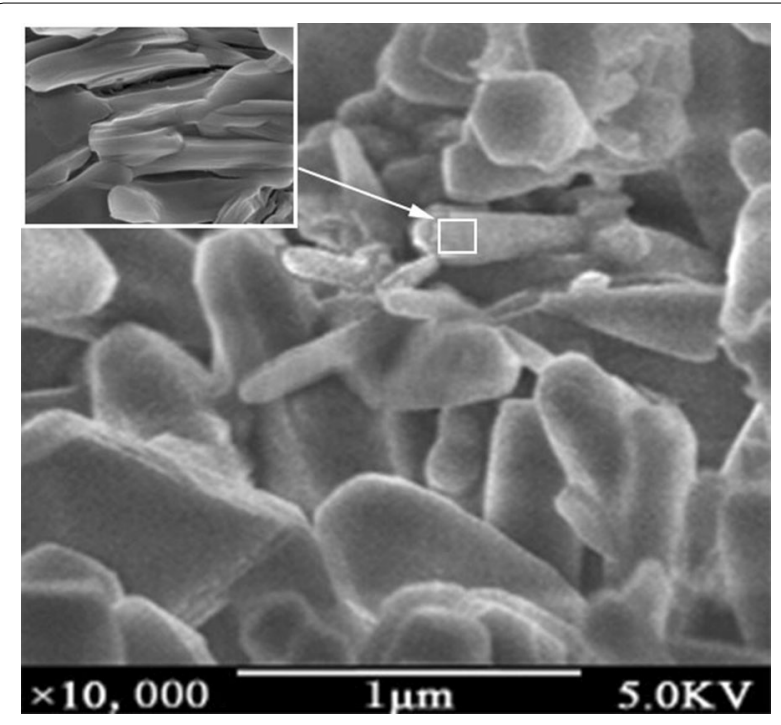

Fig. 2 SEM pictures of the $\mathrm{VAIPO}_{4}$ catalyst 


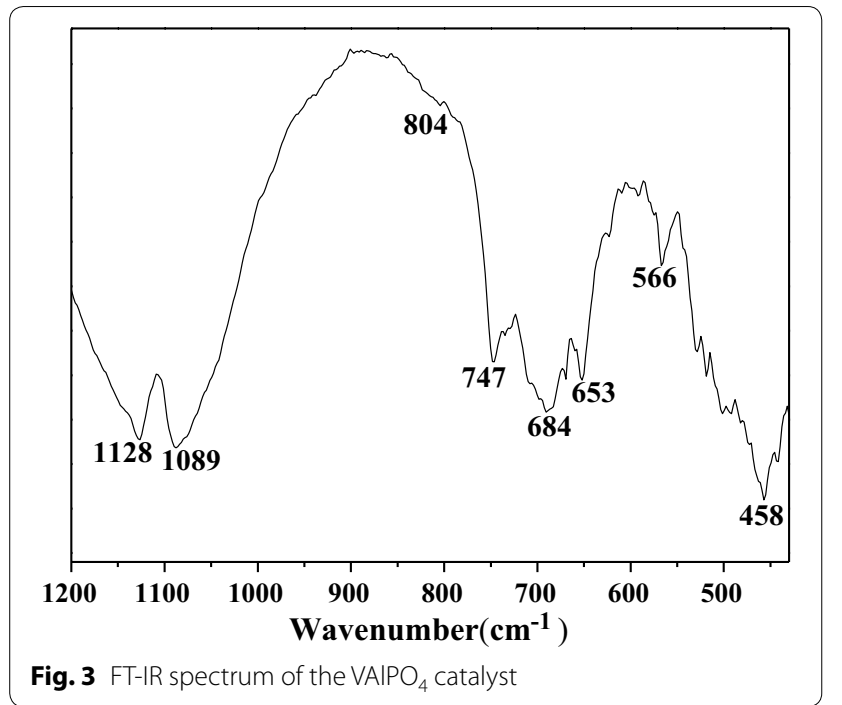

The XPS measurement shows that the surface atomic composition of the $\mathrm{VAlPO}_{4}$ catalyst is $\mathrm{V}: \mathrm{Al}: \mathrm{P}: \mathrm{O}=1.0: 4.4: 5.0: 20.0$. The V2p and O1s XPS spectra are shown in Fig. 4a, b. The binding energy of the $\mathrm{V} 2 \mathrm{p}_{1 / 2}$ and $\mathrm{V} 2 \mathrm{p}_{3 / 2}$ peaks (Fig. $4 \mathrm{a}$ ) is, respectively 524.7 and $517.6 \mathrm{eV}$ in the $\mathrm{VAlPO}_{4}$ catalyst. Compared with the $\mathrm{V} 2 \mathrm{p} 1 / 2$ and $\mathrm{V} 2 \mathrm{p} 3 / 2$ signal for $\mathrm{V}_{2} \mathrm{O}_{5}$, that is respectively $525.8 \mathrm{eV}$ and $518.3 \mathrm{eV}[20,21]$, those of the $\mathrm{VAlPO}_{4}$ catalyst slightly shifted toward lower binding energy, indicating that $\mathrm{V}(\mathrm{V})$ ions, replacing the $\mathrm{Al}(\mathrm{III})$ and/or $\mathrm{P}(\mathrm{V})$, are incorporated into the berlinite framework, resulting in oxygen vacancies in close vicinity to $\mathrm{V}(\mathrm{V})$, and possessed a higher tendency to draw electrons as compared to those in $\mathrm{V}_{2} \mathrm{O}_{5}$. Meanwhile, the $\mathrm{O}_{1 \mathrm{~s}}$ signal for the $\mathrm{VAlPO}_{4}$ catalyst (Fig. 4b) is $532.2 \mathrm{eV}$, higher than that for $\mathrm{V}_{2} \mathrm{O}_{5}$ $(\mathrm{BE}=531.6 \mathrm{eV})[20,21]$. The results further suggested that the lattice oxygen was existed on the surface of the
$\mathrm{VAlPO}_{4}$ catalyst. Thus, the catalytic activity of vanadium oxide in oxidation reactions is improved.

\section{Cyclohexane oxidation}

$\mathrm{VAlPO}_{4}$ berlinite catalyzed the oxidation of cyclohexane and the results were shown in Table 1. Leaching ratio of the metal into solution was checked by AAS analyses of the supernatant solution (see Table 1). It is found that no vanadium is leached into the solution. At the same time, the leaching tests showed that the reaction (Table 1) nearly stopped after the removal of the solid catalysts. For example, the reaction with neat cyclohexane and the supernatant after the removal of solid $\mathrm{VAlPO}_{4}$ berlinite showed the small additional conversion ratio (only $0.04 \%$ ) during the $10 \mathrm{~h}$ leaching testing. The catalyst was recycled for three times without activity loss. At the same time, according to the method proposed by Concepción et al. [3], we prepared $\mathrm{VAPO}_{4}-5$ molecular sieve and compared it with $\mathrm{VAlPO}_{4}$ berlinite as catalyst for the selective oxidation of cyclohexane with molecular oxygen under mild conditions. High metal leaching ratio was observed, which was consistent with previous results reported by Lin et al. [3, 4, 10-12]. In contrast, berlinite is more stable than porous aluminophosphate molecular sieve. Thus, The $\mathrm{VAlPO}_{4}$ berlinite is proved to be more stable than $\mathrm{VAPO}_{4}-5$ molecular sieve as heterogeneous catalyst for the selective oxidation of cyclohexane with molecular oxygen under atmospheric pressure.

For comparison, under the same reaction conditions for the oxidation of cyclohexane, we studied the catalyst of $\mathrm{AlPO}_{4}$ berlinite without the incorporation of $\mathrm{V}$ and the catalyst of $\mathrm{VAlPO}_{4}$ berlinite. $\mathrm{AlPO}_{4}$ berlinite did not exhibit any significant activity. The higher activity of $\mathrm{VAlPO}_{4}$ berlinite may be attributed to that $\mathrm{V}(\mathrm{V})$ ions are incorporated into the berlinite framework, resulting in oxygen vacancies in close vicinity to $\mathrm{V}(\mathrm{V})$, and possessed
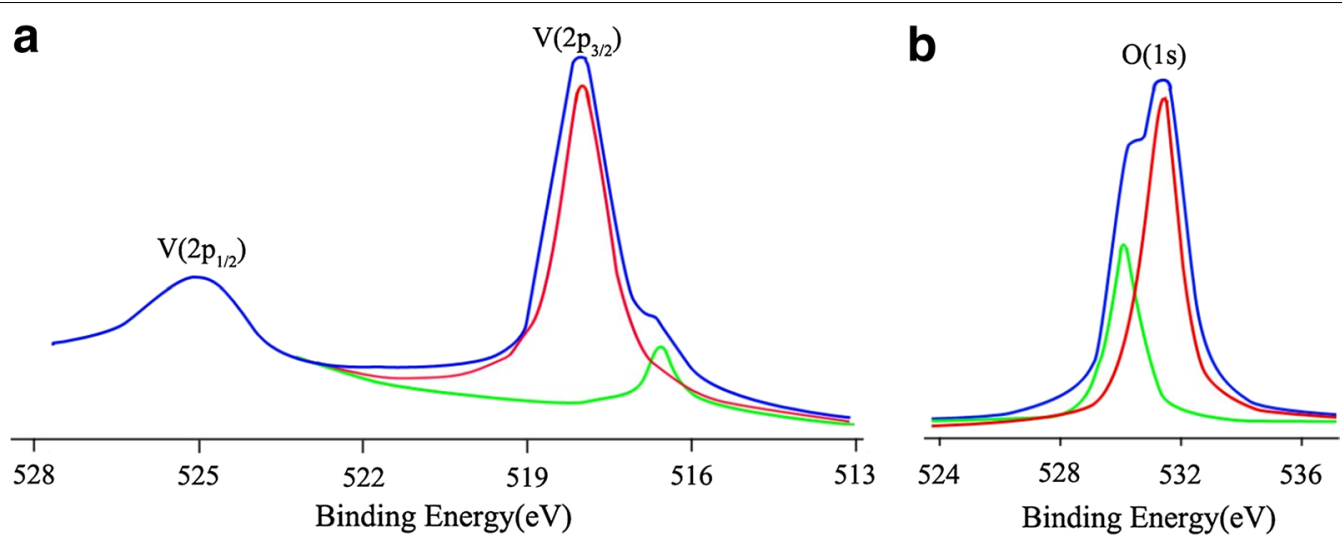

Fig. $4 \mathrm{~V} 2 \mathrm{p}(\mathbf{a})$ and O1s (b) XPS spectra of the $\mathrm{VAIPO}_{4}$ catalyst 
Table 1 Catalytic oxidation of cyclohexane over $\mathrm{VAIPO}_{4}$ berlinite and VAPO-5 molecular sieve

\begin{tabular}{|c|c|c|c|c|c|c|c|c|}
\hline \multirow[t]{2}{*}{ Catalyst } & \multirow[t]{2}{*}{$x(\%)^{a}$} & \multicolumn{3}{|c|}{$\mathrm{Si}(\%)^{\mathrm{c}}$} & \multicolumn{3}{|c|}{$[\mathrm{V}, \mathrm{Co}$ and/or $\mathrm{Mn}](\mathrm{ppb})^{\mathrm{d}}$} & \multirow[t]{2}{*}{$X(\%)^{b}$} \\
\hline & & Ol & One & Others & v & Co & $M n$ & \\
\hline $\mathrm{AlPO}_{4}$ & 0 & 0 & 0 & 0 & 0 & 0 & 0 & 0 \\
\hline VAIPO $_{4}$ & 5.9 & 69.2 & 28.6 & 1.8 & 11 & - & - & 0.04 \\
\hline VAPO-5 & 6.3 & 60.5 & 35.0 & 1.0 & 390 & - & - & 0.8 \\
\hline $\mathrm{V}_{2} \mathrm{O}_{5}$ & 2.1 & 51.3 & 44.6 & 4.1 & 610 & - & - & 1.1 \\
\hline VAIPO e & 5.7 & 68.7 & 28.9 & 2.4 & 15 & - & - & 0.09 \\
\hline $\mathrm{CoAPO}_{4}[22]$ & 3.8 & 91.3 & 7.4 & 1.3 & - & 24 & - & 0.03 \\
\hline $\mathrm{MnAPO}_{4}[22]$ & 4.1 & 93.6 & 5.6 & 0.8 & - & - & 0 & 0.01 \\
\hline $\mathrm{CoMnAPO}_{4}[22]$ & 5.2 & 60.7 & 33.7 & 0.5 & - & 15 & 8 & 0.04 \\
\hline
\end{tabular}

Cyclohexane $100 \mathrm{~mL}, \mathrm{VAIPO}_{4}$ berlinite catalyst $5 \mathrm{mg}$, acetic acid solvent $40 \mathrm{~mL}, \mathrm{O}_{2}$ pressure $0.1 \mathrm{MPa}, 348 \mathrm{~K}, 4 \mathrm{~h}$

a,b x: Cyclohexane conversion in normal and leaching test, respectively; ${ }^{\mathrm{C}} \mathrm{Si}$ : Ol, cyclohexanol; One, cyclohexanone; Others, $\mathrm{C}_{4}-\mathrm{C}_{6}$ diacids and their esters; ${ }^{\mathrm{d}}$ Concentrations of metal ion leaked into solution; ${ }^{\mathrm{e}} \mathrm{VAIPO}_{4}$ berlinite catalyst recycled for the fifth time as a catalyst in the reaction batch

a higher tendency to draw electrons as compared to those in $\mathrm{V}_{2} \mathrm{O}_{5}$. In order to check the reusability of the catalyst, it was recycled for five times without activity loss. Thus, in the oxidation of cyclohexane with molecular oxygen under mild conditions, compared with other berlinite catalysts, such as $\mathrm{AlPO}_{4}, \mathrm{CoAlPO}_{4}$ and $\mathrm{MnAlPO}_{4}$, $\mathrm{VAlPO}_{4}$ berlinite showed higher catalytic activity. Then, Factors influencing the reaction using $\mathrm{VAlPO}_{4}$ berlinite as catalyst were studied systematically, with a possible reaction mechanism also proposed.

\section{Effect of solvents}

Table 2 presents the results of oxidation of cyclohexane with molecular oxygen in the absence and presence of various solvents (acetic acid, $\mathrm{N}$-propylsulfonic acid pyridinium tetrafluoroboborate (IL), or acetonitrile), using $\mathrm{VAlPO}_{4}$ as catalyst, a reaction time of $3 \mathrm{~h}$ and a reaction temperature of $353 \mathrm{~K}$. All the batches consisted of $100 \mathrm{~mL}$ cyclohexane, $0.1 \mathrm{MPa} \mathrm{O}_{2}, 5 \mathrm{mg} \mathrm{VAlPO}_{4}$ and $20 \mathrm{~mL}$ solvent. It was found that in the absence of solvent, the conversion of cyclohexane, the selectivity to KA oil were only 3.0 and $94.3 \%$, respectively. When a solvent was employed, the conversion of cyclohexane, the selectivity to KA oil (both cyclohexanol and cyclohexanone) increased to above 4.1 and $95.8 \%$, respectively. This indicates that the solvent stimulated the oxidation of cyclohexane with molecular oxygen. The stimulation by the solvent was in the order acetic acid $>\psi \mathrm{IL}>\psi$ acetonitrile $>\psi$ no solvent. The above result reveals that acetic acid as solvent is favorable for the oxidation of cyclohexane with molecular oxygen, which is probably due to the cyclohexane has better solubility in acetic acid [23].

\section{Effect of reaction temperature}

Figure 5 presents the effect of reaction temperature on cyclohexane conversion and selectivities for the main product, the intermediate product, and by-products. On increasing reaction temperature, the conversion of cyclohexane increased rapidly over the temperature range $333-373 \mathrm{~K}$, and only slightly at temperatures higher than $373 \mathrm{~K}$, approaching its maximum of $8.2 \%$. The above results indicate that the elevation of reaction temperature promoted the conversion of cyclohexane. The selectivity of KA oil increased with on moving from 333 to $353 \mathrm{~K}$, attaining a maximum of $97.2 \%$ at $353 \mathrm{~K}$, before decreasing at higher temperatures. The selectivity for the intermediate product cyclohexyl hydroperoxide (CHHP) first increased and then decreased during the reaction temperature range $333-383 \mathrm{~K}$. This could be due to the fact that a higher temperature accelerates the decomposition of the intermediate CHHP to main product KA oil [24]. The selectivities for by-products both acids and esters increased with the increase of reaction temperature. For all the reaction temperature points tested, the selectivity for main product KA oil was much larger than that for both the intermediate CHHP and by-products (acids and esters). Although a higher conversion of cyclohexane could be attained at high temperature, too high a temperature reduced the selectivity of KA oil-possibly due to

Table 2 Conversions of cyclohexane and selectivities to products in different solvents

\begin{tabular}{llllll}
\hline Solvent & Conversion (\%) & \multicolumn{4}{l}{ Selectivity (\%) } \\
\cline { 3 - 6 } & & KA oil $^{\mathbf{a}}$ & Acids $^{\mathbf{b}}$ & Esters $^{\mathbf{c}}$ & CHHP $^{\mathbf{d}}$ \\
\hline Without & 3.0 & 94.3 & 0.3 & 0.2 & 5.2 \\
Acetic acid & 6.8 & 97.2 & 1.6 & 0.5 & 0.7 \\
IL & 5.9 & 96.3 & 1.2 & 0.9 & 1.6 \\
Acetonitrile & 4.1 & 95.8 & 1.2 & 1.3 & 1.7 \\
\hline
\end{tabular}

Cyclohexane $100 \mathrm{~mL}, \mathrm{VAIPO}_{4}$ berlinite catalyst $5 \mathrm{mg}$, acetic acid solvent $40 \mathrm{~mL}$, $\mathrm{O}_{2}$ pressure $0.1 \mathrm{MPa}, 353 \mathrm{~K}, 4 \mathrm{~h}$

a Cyclohexanol and cyclohexanone; ${ }^{\mathrm{b}} \mathrm{C}_{4}-\mathrm{C}_{6}$ diacids; ${ }^{\mathrm{c}}$ synthesized by the reaction of $\mathrm{C}_{4}-\mathrm{C}_{6}$ diacids and cyclohexanol; ${ }^{\mathrm{d}}$ cyclohexyl hydroperoxide 


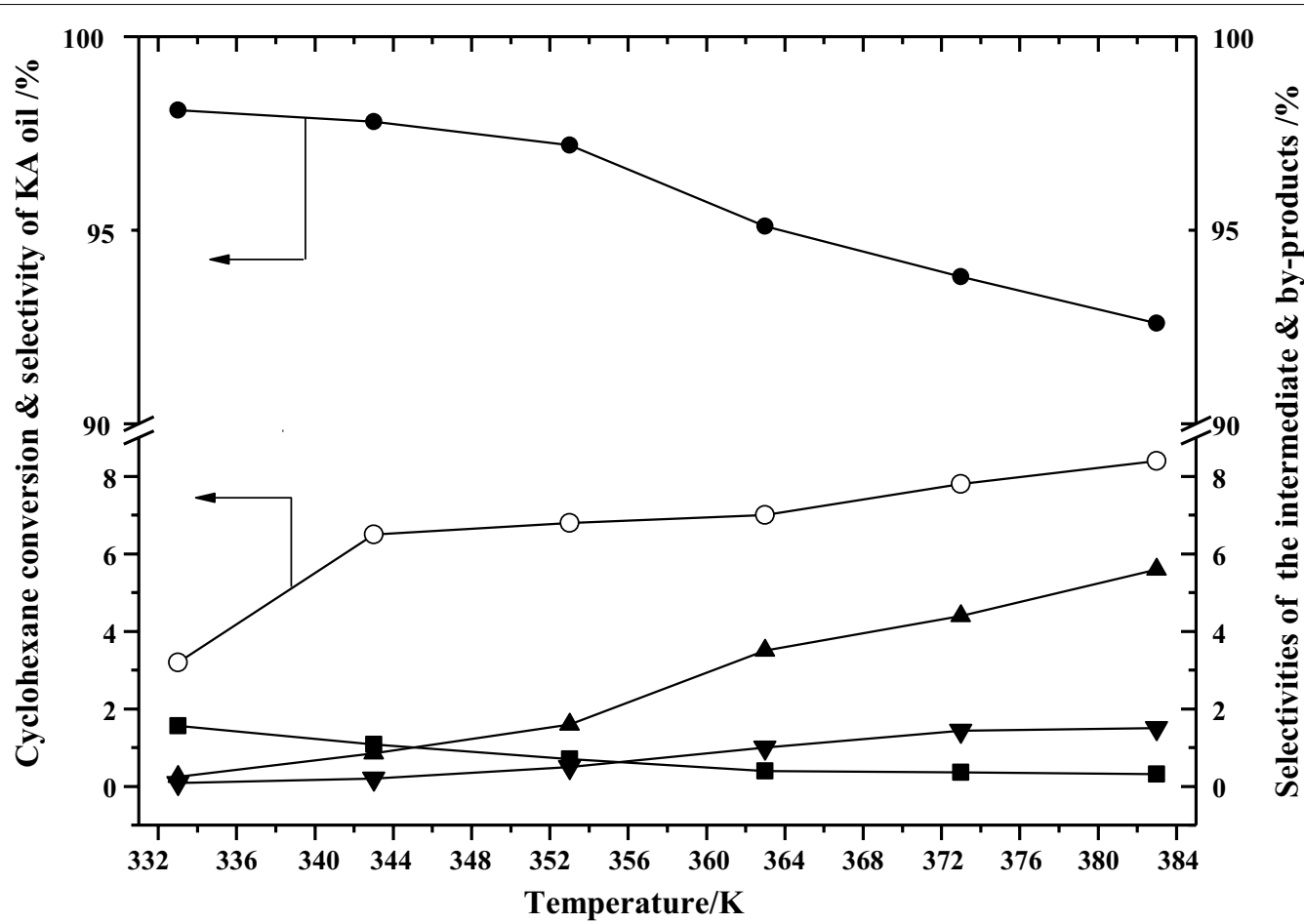

Fig. 5 Effect of reaction temperature on cyclohexane conversion, selectivities for the main product, intermediate product, and by-products. Reaction conditions: cyclohexane $100 \mathrm{~mL}, V_{A} \mathrm{PO}_{4}$ berlinite catalyst $5 \mathrm{mg}$, acetic acid solvent $40 \mathrm{~mL}, \mathrm{O}_{2}$ pressure $0.1 \mathrm{MPa}$, reaction time: $4 \mathrm{~h}$. (White circle) cyclohexane conversion; (Black circle), (Black square), (Black up-pointing triangle) and (Black down-pointing triangle) selectivity for KA oil, $\mathrm{CHHP}$, acids and esters, respectively. KA oil: cyclohexanol and cyclohexanone; CHHP: cyclohexyl hydroperoxide; acids: $\mathrm{C}_{4}-\mathrm{C}_{6}$ diacids; esters: synthesized by the reaction of $\mathrm{C}_{4}-\mathrm{C}_{6}$ diacids and cyclohexanol

the further oxidation of KA oil into acid and the synthesis of ester by the reaction from both acid and cyclohexanol [24]. Thus, the optimum reaction temperature for the oxidation of cyclohexane with molecular oxygen using under atmospheric pressure is around $353 \mathrm{~K}$.

\section{Effect of reaction time}

Figure 6 outlines the effect of reaction time on cyclohexane conversion and selectivities for the main product, the intermediate product, and by-products. With increasing reaction time, the cyclohexane conversion increased quickly within $4 \mathrm{~h}$ and only slightly over longer reaction times, reaching a value of nearly $7 \%$. The selectivity of KA oil increased, followed by a decrease, with a maximum value of $97 \%$ being achieved at a reaction time of $4 \mathrm{~h}$. On prolonging the reaction timeframe, the selectivity for the by-products both acids and esters increased gradually, while that for the intermediate product CHHP decreased slowly. These results indicate that a longer reaction time promoted the decomposition of the intermediate CHHP to the main product KA oil, but a too long reaction time resulted in the further oxidation of KA oil into acid and the synthesis of ester by the reaction from both acid and cyclohexanol. Thus, the optimum reaction time is suggested as being $4 \mathrm{~h}$.

\section{Mechanistic consideration to the oxidation of cyclohexane with molecular oxygen over the $\mathrm{VAIPO}_{4}$ catalyst}

Although mechanistic studies on the oxidation of cyclohexane with molecular oxygen in the presence of a VAlPO $_{4}$ catalyst are still in progress, it can be surmised that the reaction pathway may involve a catalytic cycle that involves a number of steps (Scheme 1). At first, the carbon in cychohexane is attacked by the nucleophilic lattice oxygen ion of $\mathrm{VAlPO}_{4}$ catalyst, forming a reaction product cyclohexanol. Meanwhile, the V in $\mathrm{VAlPO}_{4}$ catalyst lattice is reduced, leaving an oxygen vacancy at the $\mathrm{VAlPO}_{4}$ catalyst surface. Such an oxygen vacancy is then filled with oxygen from the gas phase, which simultaneously reoxidizes the reduced $\mathrm{V}$ of $\mathrm{VAlPO}_{4}$ catalyst lattice results in the recovery of the $\mathrm{VAlPO}_{4}$ catalyst. Similarly, both cyclohexanone product and cyclohexyl hydroperoxide (CHHP) intermediate could be resulted from further oxidation cyclohexanol by molecular oxygen in the presence of a $\mathrm{VAlPO}_{4}$ catalyst $[24,25]$. Then, additional further oxidation of cyclohexanone would end up in 


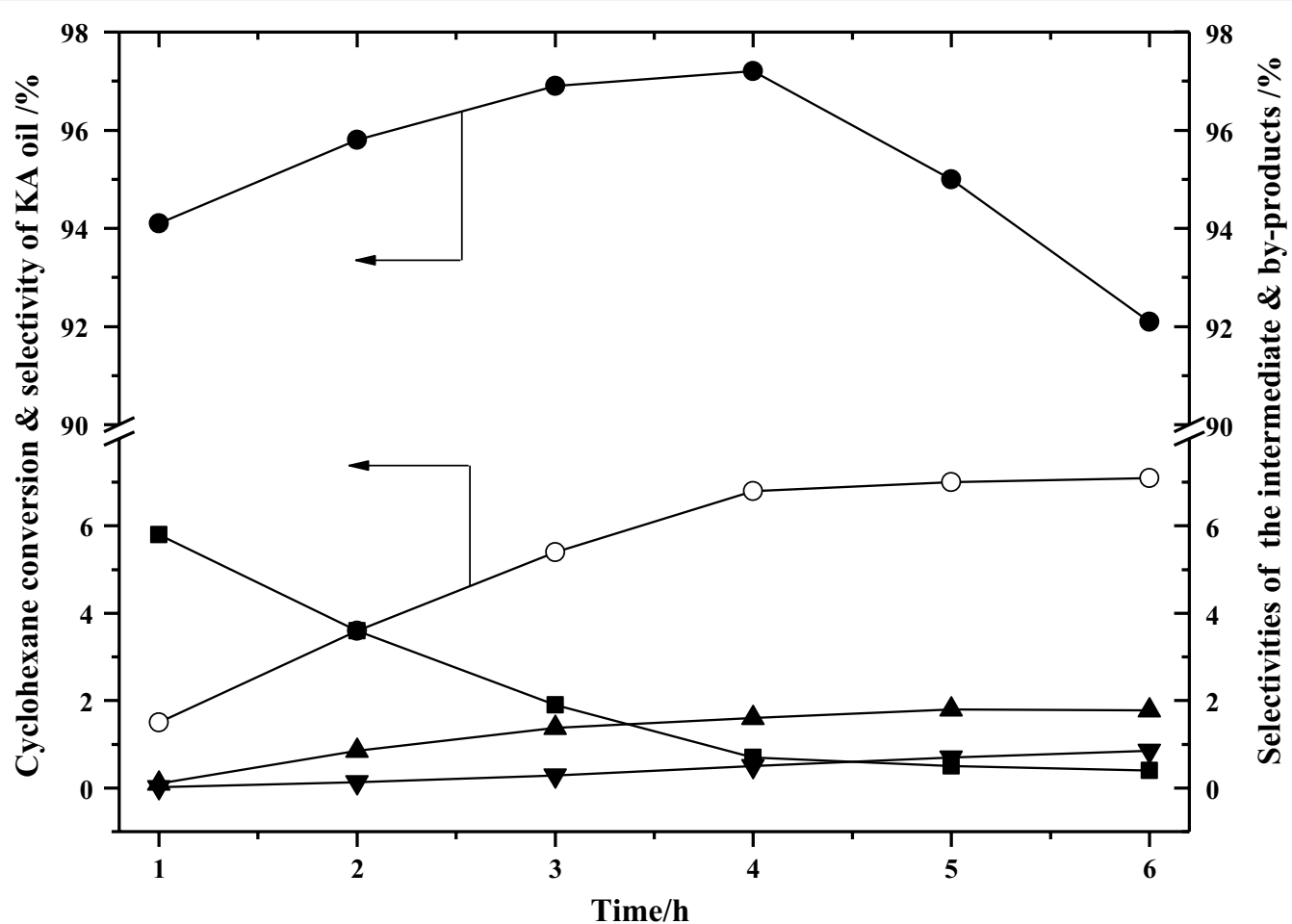

Fig. 6 Effect of reaction time on cyclohexane conversion, selectivities for the main product, intermediate product, and by-products. Reaction conditions: cyclohexane $100 \mathrm{~mL}, V_{A I P O}$ berlinite catalyst $5 \mathrm{mg}$, acetic acid solvent $40 \mathrm{~mL}, \mathrm{O}_{2}$ pressure $0.1 \mathrm{MPa}$, reaction time: $4 \mathrm{~h}$. (White circle) cyclohexane conversion; (Black circle), (Black square), (Black up-pointing triangle) and (Black down-pointing triangle) selectivity for KA oil, $\mathrm{CHHP}$ acids and esters, respectively. KA oil: cyclohexanol and cyclohexanone; $\mathrm{CHHP}$ : cyclohexyl hydroperoxide; acids: $\mathrm{C}_{4}-\mathrm{C}_{6}$ diacids; esters: synthesized by the reaction of $\mathrm{C}_{4}-\mathrm{C}_{6}$ diacids and cyclohexanol

ring-opened acid by-products, which can be esterified by cyclohexanol, generating the ester by-products [24, 25]. It must be noted that the oxidation depth of cyclohexane is closely related to the reaction conditions, especially the reaction temperature. In general, the depth of cyclohexane oxidation increases with the increase of the reaction temperature. For this reason, only a lower than $1 \%$ acids by-products was formed because of cyclohexane oxide deeply during the manufacture of KA oil (cyclohexanol and cyclohexanone) by the oxidation of cyclohexane over the $\mathrm{VAlPO}_{4}$ catalyst under mild conditions (i.e. $333 \sim 383 \mathrm{~K}$, atmospheric pressure).

\section{Conclusions}

A new material, $\mathrm{VAlPO}_{4}$ berlinite, has been prepared and characterized. It is proved that the vanadium is incorporated into the framework of $\mathrm{AlPO}_{4}$ berlinite. The catalytic activity of $\mathrm{VAlPO}_{4}$ berlinite in cyclohexane oxidation is higher than that of $\mathrm{CoAPO}_{4}$ or $\mathrm{MnAPO}_{4}$ under the same conditions and similar loads of cobalt and manganese.
Furthermore, $\mathrm{AlPO}_{4}$ berlinite without the incorporation of any metal is not active in the oxidation of cyclohexane with molecular oxygen under mild conditions. Although the catalytic activity of $\mathrm{VAPO}_{4}-5$ molecular sieve is similar to that of $\mathrm{VAlPO}_{4}$ berlinite under the same conditions, high leaching ratio of vanadium into the solution is observed when $\mathrm{VAPO}_{4}-5$ molecular sieve is used as catalyst. Meanwhile, the mechanism for the oxidation of cyclohexane with molecular oxygen over the $\mathrm{VAlPO}_{4}$ catalyst may have resulted from a catalytic cycle involving a key active intermediate species-formed from the nucleophilic addition of the lattice oxygen ion with the carbon in cyclohexane-that leaves an oxygen vacancy at the $\mathrm{VAlPO}_{4}$ catalyst surface, which further splits oxygen molecules into atoms and then acts as a reservoir that can take up these atoms and then release them to form molecules. In conclusion, $\mathrm{VAlPO}_{4}$ berlinite is an efficient recyclable heterogeneous catalyst for the selective oxidation of cyclohexane with molecular oxygen under mild conditions. 


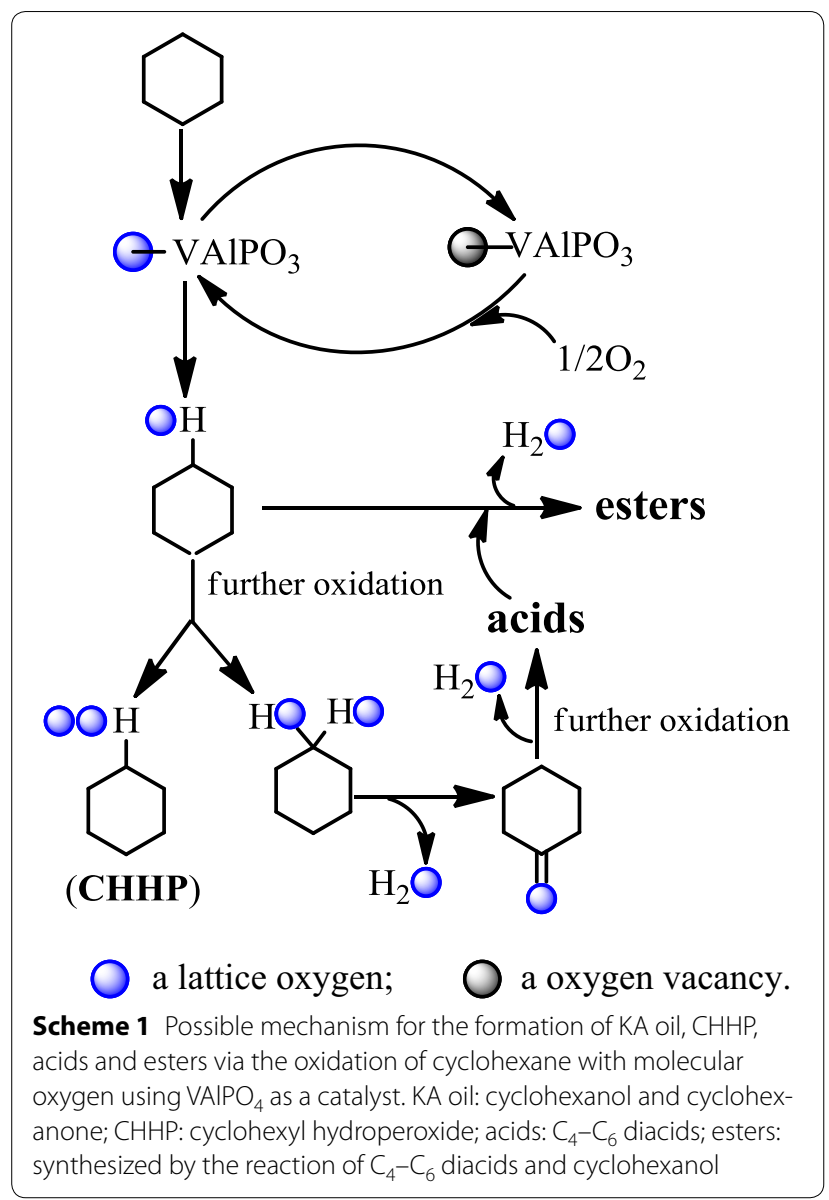

\section{Additional files}

Additional file 1. The GC-MS of reaction products.

Additional file 2. The HPLC of reaction products.

\section{Authors' contributions}

This study was conceived as a result of discussion between DLS and YXF. The synthesis and characterization of the $\mathrm{VAIPO}_{4}$ catalyst and its catalytic performance evaluation were carried out by $\mathrm{YH}$. The spectroscopic analysis was performed by DLS, who proposed also the reaction mechanism of the selective oxidation of cyclohexane with oxygen over the $\mathrm{VAIPO}_{4}$ catalyst. The manuscript was wrote by DLS. All authors read and approved the final manuscript.

\section{Acknowledgements}

We are grateful for the financial support provided by the Science and Technology Program of Guangzhou (No. 201607010166), China.

\section{Competing interests}

The authors declare that they have no competing interests.

\section{Ethical approval and consent to participate}

Not appliable.

\section{Publisher's Note}

Springer Nature remains neutral with regard to jurisdictional claims in published maps and institutional affiliations.
Received: 19 December 2017 Accepted: 21 March 2018

Published online: 04 April 2018

\section{References}

1. Zhou LP, Xu J, Miao H, Wang F, Li XQ (2005) Catalytic oxidation of cyclohexane to cyclohexanol and cyclohexanone over $\mathrm{CO}_{3} \mathrm{O}_{4}$ nanocrystals with molecular oxygen. Appl Catal A 292:223-228

2. Punniyamurthy T, Velusamy S, lqbal J (2005) Recent advances in transition metal catalyzed oxidation of organic substrates with molecular oxygen. Chem Rev 105:2329-2364

3. Concepción P, Corrna A, Lòpez Nieto JM, Pérez-Pariente J (1996) Selective oxidation of hydrocarbons on $\mathrm{V}$ - and/or Co-containing aluminophosphate (MeAPO-5) using molecular oxygen. Appl Catal A Gen 143:17-28

4. Wang YJ, Xie J, Wei Y (2009) Immobilization of manganese tetraphenylporphyrin on $\mathrm{Au} / \mathrm{SiO}_{2}$ as new catalyst for cyclohexane oxidation with air. Catal Commun 11:110-113

5. Rokita M, Handke M, Mozgawa W (1998) Spectroscopic studies of polymorphs of $\mathrm{AlPO}_{4}$ and $\mathrm{SiO}_{2}$. J Mol Struct 450:213-217

6. Christie DM, Chelikowsky JR (1998) Structural properties of a-Berlinite (AIPO $)$. Phys Chem Minerals 25:222-226

7. Dryden DM, Tan GL, French RH (2014) Optical properties and van der Waals-London dispersion interactions in berlinite aluminum phosphate from vacuum ultraviolet spectroscopy. J Am Ceram Soc 97:1143-1150

8. Rokita M, Handke M, Mozgawa W (2000) The $\mathrm{AlPO}_{4}$ polymorphs structure in the light of raman and spectroscopy studies. J Mol Struct 555:351-356

9. Vippola M, Ahmaniemi S, Keranen J, Vuoristo P, Lepisto T, Mantyla T, Olsson E (2002) Aluminum phosphate sealed alumina coating: characterization of microstructure. Mater Sci Eng, A 323:1-8

10. Modén B, Zhan BZ, Dakka J, Santiesteban JG, Iglesia E (2006) Kinetics and mechanism of cyclohexane oxidation on MnAPO-5 catalysts. J Catal 239:390-401

11. Devika S, Palanichamy M, Murugesan V (2011) Vapour phase oxidation of cyclohexane over CeAIPO-5 molecular sieves. J Mol Catal A Chem 351:136-142

12. Modén B, Zhan BZ, Dakka J, Santiesteban JG, Iglesia E (2007) Reactant selectivity and regiospecificity in the catalytic oxidation of alkanes on metal-substituted aluminophosphates. J Phys Chem C 111(3):1402-1411

13. Corà F, Richard C, Catlow A (2001) lonicity and framework stability of crystalline aluminophosphates. J Phys Chem B 105(42):10278-10281

14. Pawlig O, Trettin R (2000) In-situ DRIFT spectroscopic investigation on the chemical evolution of zinc phosphate acid-base cement. Chem Mater 12:1279-1287

15. Frost RL, Scholz R, López A, Xi Y-F, Queiroz CS, Belotti FM, Filho MC (2014) Raman, infrared and near-infrared spectroscopic characterization of the herderite-hydroxylherderite mineral series. Spectrochim Acta Part A Mol Biomol Spectrosc 118:430-437

16. Sun DL, Deng JR, Chao ZS et al (2007) Catalysis over zinc-incorporated berlinite $\left(\mathrm{ZnAlPO}_{4}\right)$ of the methoxycarbonylation of 1,6-hexanediamine with dimethyl carbonate to form dimethylhexane-1,6-dicarbamate. Chem Cent J 1:27-35

17. Wang Y, Pan L, Li Y, Gavilyuk Al (2014) Hydrogen photochromism in $\mathrm{V}_{2} \mathrm{O}_{5}$ layers prepared by the sol-gel technology. Appl Surf Sci 314:384-391

18. Aslam M, Iqbal, Ismail Ml, Almeelbi T, Salah N, Chandrasekaran A, Hameed $\mathrm{A}$ (2014) Enhanced photocatalytic activity of $\mathrm{V}_{2} \mathrm{O}_{5}-\mathrm{ZnO}$ composites for the mineralization of nitrophenols. Chemosphere 117:115-123

19. Guliants W, Benziger JB, Sundaresan S, Wachs IE, Jehng J-M, Roberts JE (1996) The effect of the phase composition of model VPO catalysts for partial oxidation of $n$-butane. Catal Today 28(4):275-295

20. Meng Y-L, Wang T, Chen S, Zhao Y-J, Ma X-B, Gong J-L (2014) Selective oxidation of methanol to dimethoxymethane on $\mathrm{V}_{2} \mathrm{O}_{5}-\mathrm{MoO} 3 / \mathrm{Y}-\mathrm{Al}_{2} \mathrm{O}_{3}$ catalysts. Appl Catal B Environ 160-161:161-172

21. Hu X-Y, Li CH-Y, Yang CH-H (2015) Studies on lattice oxygen utilization during catalytic conversion of $n$-heptane activated by $\mathrm{V}_{2} \mathrm{O}_{5} / \mathrm{Al}_{2} \mathrm{O}_{3}$. Chem Eng J 263:113-118

22. Sun D-L, Chao Z-S (2013) $\mathrm{MeAPO}_{4}$ berlinite as an effective catalyst for mild oxidation of cyclohexane. Adv Mater Res 709:102-105 
23. Malijevská I (2003) Solid-liquid equilibrium in the acetic acid-cyclohexane and acetic acid-trichloroacetic acid systems. Fluid Phase Equilibria 211(2):257-264

24. Yang DX, Wu TB, Chen CJ, Guo WW, Liu HZ, Han BX (2017) The highly selective aerobic oxidation of cyclohexane to cyclohexanone and cyclohexanol over $\mathrm{V}_{2} \mathrm{O}_{5} @ \mathrm{TiO}_{2}$ under simulated solar light irradiation. Green Chem 19:311-318
25. Tang SP, She JL, Fu AH, Zhang SY, Tang ZY, Zhang C, Liu YC, Yin DL, Li JW (2017) Study on the formation of photoactive species in $\mathrm{XPMO}_{12-\mathrm{n}} \mathrm{V}_{\mathrm{n}} \mathrm{O}_{40}-\mathrm{HCl}$ system and its effect on photocatalysis oxidation of cyclohexane by dioxygens under visible light irradiation. Applied Catal B Environ 214:89-99

\section{Submit your manuscript to a SpringerOpen ${ }^{\circ}$ journal and benefit from:}

- Convenient online submission

- Rigorous peer review

- Open access: articles freely available online

- High visibility within the field

- Retaining the copyright to your article

Submit your next manuscript at $\boldsymbol{\nabla}$ springeropen.com 